\title{
Gastric Emptying and Lingual Lipase Activity in Cystic Fibrosis
}

\author{
M. ROULET, A. M. WEBER, ${ }^{(40)}$ Y. PARADIS, C. C. ROY, L. CHARTRAND, R. LASALLE, \\ AND C. L. MORIN \\ Hopital Sainte-Justine, Department of Pediatrics, University of Montreal, Montreal, Canada
}

\begin{abstract}
Summary
To identify gastric factors likely to contribute to fat maldigestion and malabsorption in cystic fibrosis (CF), gastric emptying time, secretion rate, and preduodenal lipolytic activity were studied. Gastric emptying of a liquid test meal and gastric acid secretion were determined in five CF teenagers with pancreatic insuficiency and in five healthy controls. During the first $h r$, the rate of gastric emptying exhibited a linear pattern in both $C F$ patients and controls. Neither the emptying time nor the gastric secretion rate was different. Lingual lipase activity was measured in eight other $C F$ patients with pancreatic insufficiency and in eight controls. Lipase activity was higher $(P<0.05)$ in $C F$ patients than in controls with values $(\overline{\mathrm{X}} \pm$ S.E. $)$ of $34.48 \pm 11.59$ and $12.65 \pm 5.60$ $\mu$ mole butyric acid $\mathrm{min}^{-1} \mathrm{ml}^{-1}$, respectively. No correlation with age or body surface was observed. Intragastric lipolysis of a butterfat triglyceride test meal was fast in both groups, but more extensive $(P<0.05)$ in $C F$ patients than in controls. The data show that in $C F$ with pancreatic insufficiency, gastric factors contributing to the first step of fat digestion are preserved. In fact, lingual lipase activity was found to be increased, and a more complete intragastric lipolysis was documented.
\end{abstract}

\section{Speculation}

In view of the normal gastric emptying time, high lingual lipase activity, and significant degree of hydrolysis of a fatty meal taking place in the stomach of $\mathrm{CF}$ patients, the use of acid-resistant lingual lipase supplements could be considered as a new approach to the treatment of the lipolytic phase defect associated with pancreatic insufficiency in cystic fibrosis.

Pancreatic enzyme preparations, alone $(4,12,38)$ or in association with drugs decreasing gastric acidity $(26,31,36,37)$, improve but do not correct the steatorrhea of cystic fibrosis (CF). Therefore, it seemed of interest to study gastric factors which could influence fat digestion and absorption in this disease.

Rapid evacuation of the stomach content has been reported in pancreatic insufficiency (PI) not related to CF $(27,29)$. It was claimed that accelerated gastric emptying might overwhelm limited pancreatic reserves and contribute to maldigestion. Lingual lipase is another factor recently shown to be involved in the first step of fat digestion. This lipase originates in the glands of von Ebner located at the posterior third of the tongue (18), is active at the acid $\mathrm{pH}$ of the stomach, and plays a role in fat digestion ( 1 , $17,18)$ and emulsification $(19,32)$. This study was undertaken to get information about gastric emptying time, gastric acid secretion, and lingual lipase activity in CF with PI.

\section{PATIENTS AND METHODS}

\section{PATIENTS}

Gastric emptying and gastric acid secretion were studied in five teenage CF patients ( $17.9 \pm 0.5$ years) and in five healthy controls
(21.5 \pm 0.5 years). Lingual lipase activity was measured in eight other CF patients $(7.3 \pm 2.2$ years) and in eight controls $(21.9 \pm$ 6.0 years). Five members of the latter control group were healthy, two had Crohn's ileitis, and one suffered from chronic nonspecific diarrhea. Although controls were significantly older $(P<0.05)$ than both CF groups, they were comparable in terms of weight, height, and body surface. They had a normal stool fat excretion. The diagnosis of CF had previously been confirmed by abnormal sweat chloride determinations ( $>60 \mathrm{mEq} / \mathrm{liter}$ ), and they all had clinical evidence of pancreatic insufficiency with steatorrhea $(>7$ $\mathrm{g} /$ day) requiring enzyme replacement therapy.

Subjects or their parents were informed of the experimental nature of the study, and a written consent was obtained after approval of the protocol by the Ethics Committee.

\section{GASTRIC EMPTYING}

After an overnight fast, a 12 Fr nasogastric tube (Salem Sump Tube; Argyle, St. Louis, MO) was placed under fluoroscopy, and the stomach was washed out with saline. Fifteen min later, the patients, who remained in an upright position sitting on a chair throughout the study, drank the first $50 \mathrm{ml}$ of a test meal $(750 \mathrm{ml} /$ $1.73 \mathrm{~m}^{2}$ ). The remainder was given through the feeding tube over a 5 -min period. The test meal consisted of corn oil $(40 \mathrm{~g} /$ liter $)$, dextrose $(50 \mathrm{~g} /$ liter $)$, and phenol red as a dilution marker $(30 \mathrm{mg} /$ liter). Its osmolality was $245 \mathrm{mOsm} / \mathrm{kg} \mathrm{H}_{2} \mathrm{O}$, and its $\mathrm{pH}$ was 7.0 . After thorough blending, it was given at room temperature. Gastric content was evaluated at time $15,30,45$, and $60 \mathrm{~min}$ by the double sampling technique of George (10). Essentially, this technique consists in determining the concentrations of phenol red before and after the intragastric adjunction of a known amount of the marker. This method was modified to take into account the endogenous gastric secretions of $\mathrm{Na}^{+}, \mathrm{K}^{+}$, and $\mathrm{H}^{+}$by measuring ch'oride concentration (21). The test ended by complete gastric aspiration and washing out of the stomach. Determination of phenol red was done on a Beckman DB-G spectrophotometer at $560 \mathrm{~nm}$ and gastric acid by chloride determination (34).

\section{LINGUAL LIPASE AND INTRAGASTRIC LIPOLYSIS}

After an overnight fast, control and CF patients were given 50 $\mathrm{ml} / 1.73 \mathrm{~m}^{2}$ of cream ( $10 \%$ butterfat). Ten min later, a $10 \mathrm{Fr}$ nasogastric tube (Salem Sump Tube; Argyle, St. Louis, MO) was placed in the stomach, and the gastric content was aspirated. One ml was transferred to a test tube containing chloroform:methanol (2:1) and kept at $-20^{\circ} \mathrm{C}$ until lipid extraction (7). The products of lipolysis were separated by thin-layer chromatography (28) and quantitated by titration of fatty acids after hydrolysis (25). A small aliquot of gastric content was immediately processed. After a 20min centrifugation at $1600 \times \mathrm{g}$, lipase activity was determined on 10 to $50 \mu \mathrm{l}$ of supernatant using a modification of Fredrikzon's technique (8). The tributyrin substrate (Sigma Chemical Co., St. Louis, MO) was emulsified with gum arabic $1 \%$ (Fisher Scientific Company, Fair Lawn, NJ) using 2 min of sonication at $60 \mathrm{~W}$ (Sonic Dismembrator; Artek System Corporation, Farmingdale, 
NY). Released butyric acid was manually titrated by $\mathrm{NaOH} 0.01$ $M$ with a micropipet (Digipet; Manostat, New York, NY) for the next 15 min at pH 5.5 (Radiometer, pH Meter Type PHM $26 \mathrm{c}$; Copenhagen, Denmark).

\section{STATISTICS}

Differences in mean values were tested by the Student $t$ test. In the presence of nongaussian distributions, the nonparametric test of Mann-Whitney (35) was used. The gastric emptying curves were analyzed by stepwise polynomial regression technique (5). $P$ values less than 0.05 were considered significant. Results were expressed as mean \pm S.E.

\section{RESULTS}

\section{GASTRIC EMPTYING AND GASTRIC ACID SECRETION}

Before the study, the reliability of the double sampling technique was confirmed in a normal volunteer. After administering each amount of phenol red marker at $15,30,45$, and $60 \mathrm{~min}$, the gastric content was withdrawn, measured, sampled, and finally returned to the stomach. The volume was compared to the one estimated by measuring marker dilution. The aspirated volume was invariably smaller but the difference was not significant. This was due to incomplete aspiration of gastric content, as demonstrated by the recovery of some residual marker. Thereafter, gastric washouts were carried out at the termination of the studies, and in eight subjects, a very good linear correlation $(r=0.9186 ; P<$ 0.005 ) was found between the volumes recovered $60 \mathrm{~min}$ after ingestion and those calculated.

During the first $60 \mathrm{~min}$, gastric emptying exhibited a similar linear pattern in CF patients and controls (Fig. 1). The time required for the volume in the stomach to fall by one-half was $28.1 \pm 1.9 \mathrm{~min}$ in CF as compared to $35.5 \pm 3.8$ in controls, a difference which was not significant. The rate of gastric secretion as determined by chloride concentration was comparable in the two groups at each interval of $15 \mathrm{~min}$.

\section{LINGUAL LIPASE AND INTRAGASTRIC LIPOLYSIS}

With emulsified tributyrin as substrate, linear kinetics were obtained, and the correlation coefficients were constantly higher than 0.955 . To ensure that no pancreatic lipase could have been present in the gastric content, samples suspected of being contaminated with bile were discarded. Furthermore, lipase activity was

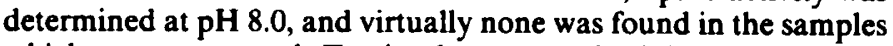
which were processed. To simulate more physiologic conditions, the tributyrin substrate was compared to triolein. With the latter,

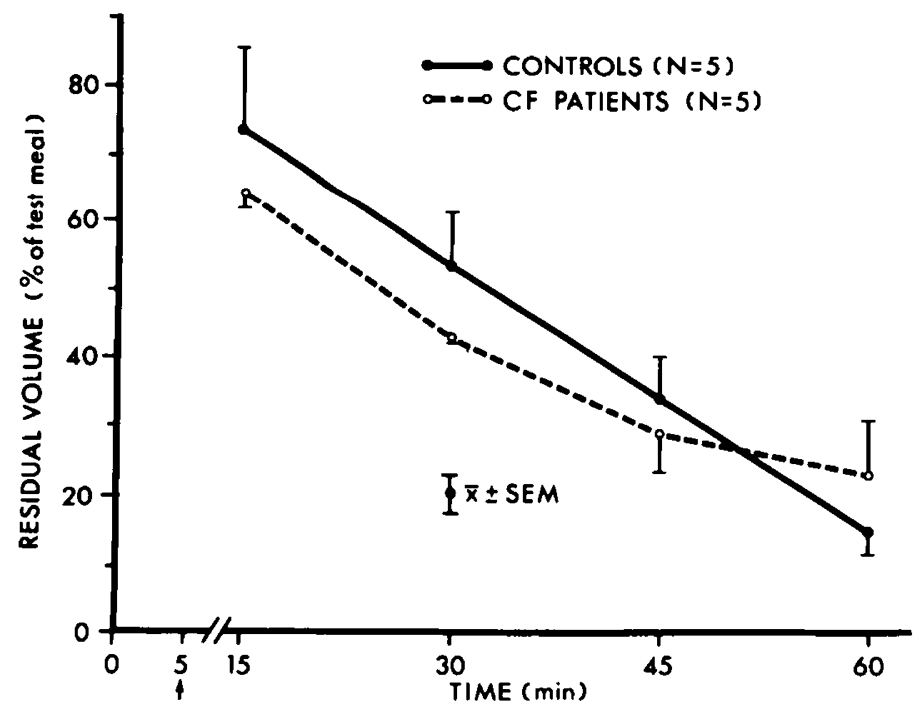

Fig. 1. Gastric emptying rate of a liquid test meal in $C F$ patients and controls.

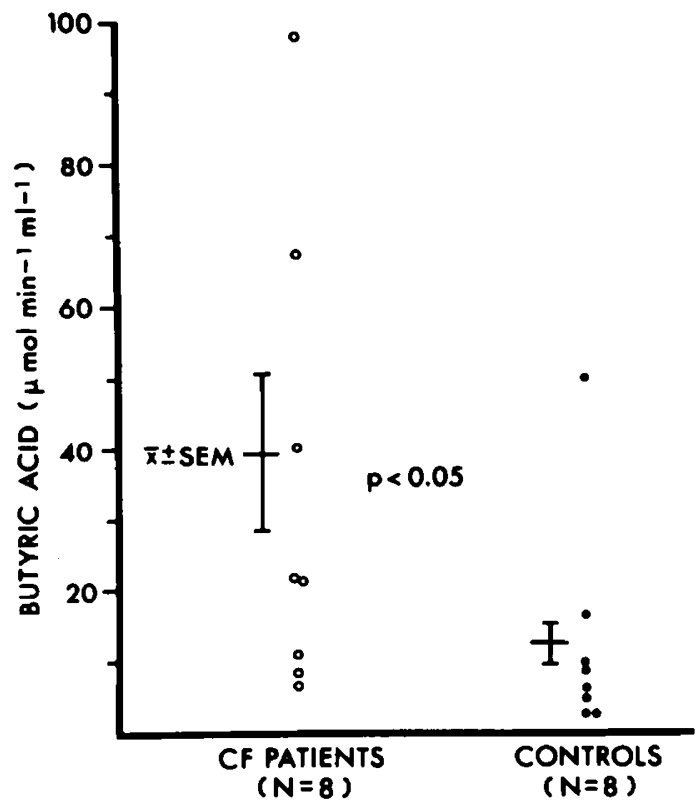

Fig. 2. Intragastric lipase activity in $\mathrm{CF}$ patients and controls.

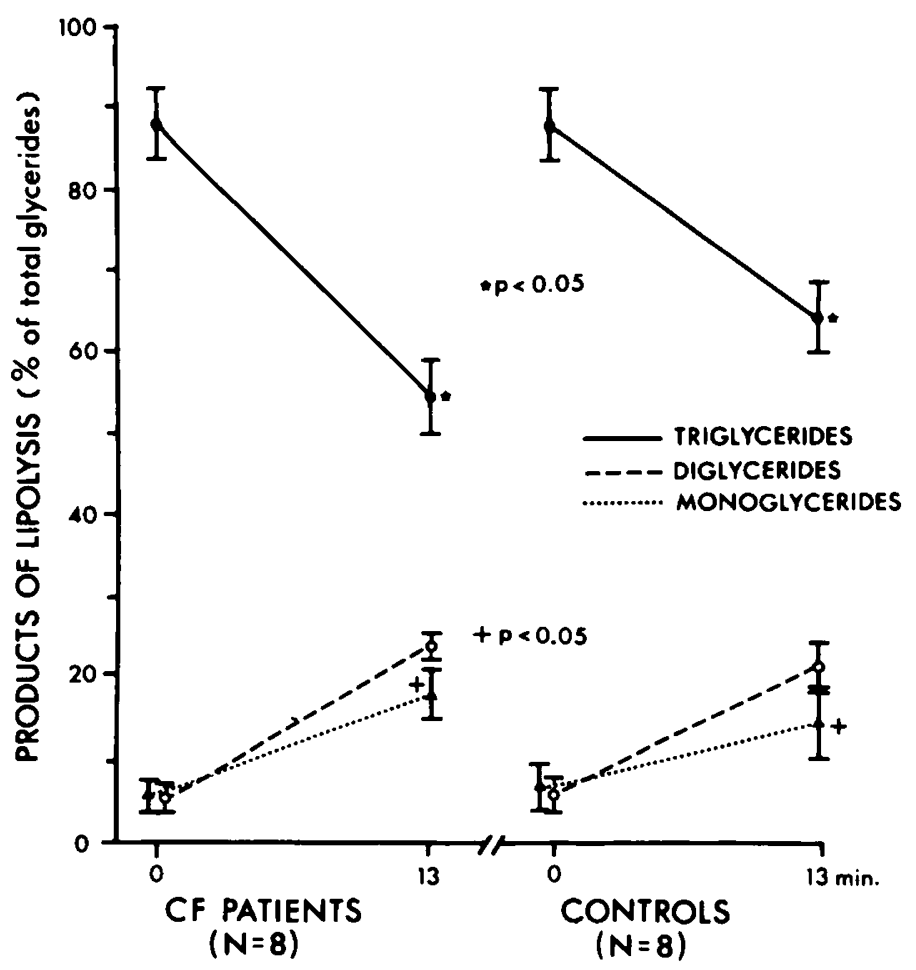

Fig. 3. Rate of intragastric lipolysis of cream (10\% butterfat) in CF patients and controls.

lipase activity was 1000 times lower, and linear kinetics were more difficult to obtain. However, a good linear correlation $(r=0.776$; $P<0.05$ ) was found between the activities against these two triglycerides.

The total volume recovered by gastric aspiration $10 \mathrm{~min}$ after ingestion of the test meal and endogenous secretions measured by chloride determination did not differ between CF patients and controls. The average $\mathrm{pH}$ of $3.9 \pm 0.4$ (range, 1.7 to 5.1 ) found in the former was comparable to the mean $\mathrm{pH}$ of $4.3 \pm 0.4$ (range, 3.0 to 5.8 ) in the latter. Despite a wide range of values and some overlap, lipase activity was significantly higher in CF patients than in controls (Fig. 2). The values were $34.5 \pm 11.6$ and $12.6 \pm$ $5.6 \mu$ moles butyric acid $\mathrm{min}^{-1} \mathrm{ml}^{-1}$, respectively. No correlation with age or body surface was observed.

The rate of intragastric lipolysis is represented on Figure 3. In 
CF patients, the extent of triglyceride hydrolysis of $33.0 \pm 3.0 \%$ was associated with a rate of monoglyceride generation of $13.0 \pm$ $2.0 \%$. These values were higher $(P<0.05)$ than the figures of 25.0 \pm 3.0 and $7.9 \pm 1.9$ found in the control group. However, diglycerides and free fatty acids production was comparable in CF patients and in controls.

\section{DISCUSSION}

These data suggest that in CF with PI gastric factors contributing to the first step of fat digestion are preserved. In children, gastric acid secretion has been shown to vary with weight (13). Inasmuch as height, weight, and body surface were identical for the two groups in both studies, the age discrepancy is unlikely to account for the results.

For the study of gastric emptying using a liquid meal, the double sampling technique of George $(10)$ is presently the most suitable nonradioactive method (33). The presence of a nasogastric tube has not been shown to modify the emptying rate (3), and phenol red has been accepted as a reliable marker $(9,24)$. Because of its water solubility and its adsorption to proteins $(9,14,16)$, the reliability of phenol red to assess water movements applies only when a protein-free test meal is fed. The gastric emptying of a liquid meal depends principally on its volume, $\mathrm{pH}$, fat content, and osmolality $(22,30,33)$. Using a liquid test meal of comparable composition, authors have also obtained a linear pattern (15). However, definite conclusions on gastric emptying in CF await further studies using solid fatty meals and liposoluble markers.

Tributyrin is a well-accepted substrate for lingual and pancreatic lipase determination $(6,8)$. Furthermore, in the present study, a good linear correlation was obtained between activities against tributyrin and triolein, a more physiologic substrate. The wide variation in lingual lipase has been previously documented in normal adults and premature infants (20). Its higher value in CF with PI might well reflect a compensatory mechanism similar to the one postulated for the augmentation of salivary $\alpha$-amylase in saliva (11) and in blood (2).

Intragastric lipolysis is increased in CF patients with PI. Lipolytic products are thought to slow gastric emptying when they enter the duodenum $(23,30)$. This explains the rapid gastric emptying reported in adults with pancreatic insufficiency $(27,29)$. It is tempting to speculate that the normal gastric emptying time observed in CF with PI, but not in PI of other origin, might be related to increased production of hydrolyzed fat in the stomach of CF patients.

The implications of effective intragastric lipolysis in CF cannot be minimized. It has been shown in rats that this preliminary hydrolysis is essential for lipid digestion and for fat and bile acid absorption when lipolytic mechanisms are stressed (32). A correlation between steatorrhea, fecal bile acid loss, and lingual lipase has yet to be documented in CF. However, to obtain more complete fat hydrolysis, supplements of lingual lipase might be considered. Its resistance to acid and activity which is independent of bile acids might well represent ideal characteristics for its use in PI of CF origin.

\section{REFERENCES AND NOTES}

1. Cohen, M., Morgan, R. G. H., and Hofmann, A. F.; Lipolytic activity of human gastric and duodenal juice against medium and long chain triglycerides. Gastroenterology, 60: 1 (1971).

2. Davidson, G. P., Koheil, A., and Forstner, G. G.: Salivary amylase in cystic fibrosis; a marker of disordered autonomic function. Pediatr. Res., 12: 967 (1978).

3. Delin, N. A., Axelsson, B., Johansson, C., and Poppen, B.: Comparison of gamma camera and withdrawal methods for the measurement of gastric emptying. Scand. J. Gastroenterol., 13: 867 (1978).

4. DiMagno, E. P., Malagelada, J. R., Go, V. L. W., and Moertel, C. G.: Fate of orally ingested enzymes in pancreatic insufficiency, Comparison of two dosages schedules. N. Engl. J. Med., 296: 1318 (1977).

5. Draper, N. R., and Smith, H.: In: Applied Regression Analysis. p. 178 (John Wiley \& Sons, New York, 1966).

6. Erlanson, C., and Borgström, B.: Tributyrin as a substrate for determination of lipase activity of pancreatic juice and small intestinal content. Scand. J. Gastroenterol., 5: 293 (1970).
7. Folch, J., Lees, M., and Stanley, G. H. S.: A simple method for the isolation and purification of total lipids from animal tissues. J. Biol. Chem., 226: 497 (1957). . Fredrikzon, B., and Hernell, O.: Role of feeding on lipase activity in gastric contents. Acta Paediatr. Scand., 66: 479 (1977),

9. French, A. B., Brown. I. F., Good, C. J., and McLeod, G. M.: Comparison of phenol red and polyethyleneglycol as nonabsorbable markers for the study of intestinal absorption in humans. Am. J. Dig. Dis., 13: 558 (1968).

10. George, J. D.: New clinical method for measuring the rate of gastric emptying; the double sampling test meal. Gut. 9: 237 (1968).

11. Gillard, B. K., Markman, H. C., Pedersen, S., and Feig, S. A.: The basis for increased $\alpha$-amylase activity in cystic fibrosis saliva. p. 42 (abstract). Cystic Fibrosis Club 19th Annual Meeting. New York, (1978).

12. Graham, D. Y.: Enzyme replacement therapy of exocrine pancreatic insufficiency in man. N. Engl. J. Med., 296: 1314 (1977).

13. Grand, R. J., Watkins, J. B., and Torti, F. M.: Development of the human gastrointestinal tract. A review. Gastroenterology, 70: 790 (1976).

14. Grollman, A.: The combination of phenol red and proteins. J. Biol. Chem., 64. 141 (1925).

15. Gross. R. A., Isenberg, J. I., Hogan, D., and Samloff, M. I.: Effect of fat on mealstimulated duodenal acid load, duodenal pepsin load, and serum gastrin in duodenal ulcer and normal subjects. Gastroenterology, 75 : 357 (1978).

16. Gupta, M., and Brans, Y.. W.: Gastric retention in neonates. Pediatrics, 62: 26 (1978).

17. Hamosh. M.: A review. Fat digestion in the newborn: role of lingual lipase and preduodenal digestion. Pediatr. Res., 13: 615 (1979).

18. Hamosh. M., and Burns, W. A.: Lipolytic activity of human lingual glands (Ebner). Lab. Invest., 37: 603 (1977).

19. Hamosh, M.. Klaeveman, H. L., Wolf, R. O., and Scow, R. O.: Pharyngeal lipase and digestion of dietary triglyceride in man. J. Clin. Invest., 55: 908 (1975).

20. Hamosh, M., Sivasubramanian. K. N., Salzman-Mann, C., and Hamosh, P.: Fa digestion in the stomach of premature infants. Characteristics of lipase activity. J. Pediatr., 93: 674 (1978).

21. Hunt. J. N.: A modification to the method of George for studying gastric emptying. Gut, 17: 812 (1974).

22. Hunt, J. N.: The regulation of gastric emptying. In: M. H. F. Friedman: Function of the stomach and intestine. p. 47 (University Park Press, Baltimore, 1975).

23. Hunt, J. N., and Knox, M. T.: A relation between the chain length of fatty acids and the slowing of gastric emptying. J. Physiol. (Lond.), 194: 327 (1968).

24. Ivey, K. J., and Schedl, H. P.: Gastric nonabsorbable indicators for studies in man. Gastroenterology, 59: 234 (1970).

25. Jeejeebhoy, K. N., Ahmad, S., and Kozak, G.: Determination of fecal fats containing both medium and long chain triglycerides and fatty acids. Clin. Biochem., 3: 157 (1970).

26. Kattwinkel, J., Agus, S. G., Taussig, L. M., Di Sant'Agnese, P. A., and Laster, L. The use of l-arginine and sodium bicarbonate in the treatment of malabsorption due to cystic fibrosis. Pediatrics, 50: 133 (1972).

27. Long. W. B., and Weiss. J. B.: Rapid gastric emptying of fatty meals in pancreatic insufficiency. Gastroenterology, 67: 920 (1974).

28. Marzo. A.. Ghirardi, P., Sardini, D., and Meroni. G.: Simplified measurement of monoglycerides, diglycerides, triglycerides, and free fatty acids in biological samples. Clin. Chem., 17: 145 (1971).

29. Moberg, S., and Carlberger, G.: Gastric emptying in healthy subjects and in patients with various malabsorptive states. Scand. J. Gastroenterol., 9: 17 (1974).

30. Moberg, S., and Carlberger, G.: The effect on gastric emptying of test meals with various fat and osmolar concentrations. Scand. J. Gastroenterol., 9: 29 (1974).

31. Regan, P. T.. Malagelada, J. R., DiMagno, E. P., Glanzman, S. L., and Go, V. L. W.: Comparative effects of antacids, cimetidine and enteric coating on the therapeutic response to oral enzymes in severe pancreatic insufficiency. $N$. Engl. J. Med., 297: 854 (1977).

32. Roy, C. C., Roulet, M., Lefebvre, D., Chartrand, L., Lepage, G., and Fournier, L.-A.: The role of gastric lipolysis on fat absorption and bile acid metabolism in rat. Lipids, 14: 811 (1979).

33. Sheiner, H. J.: Progress report. Gastric emptying tests in man. Gut, 16: 235 (1975).

34. Skeggs, L. T., and Hochstraser, H.: Chloride determination. Clin. Chem., 10: 918 (1964).

35. Snedecor, G. W., and Cochran, W. G.: In: Statistical Methods. Ed. 6, p. 130 (Iowa State University Press, Ames, IA, 1967).

36. Veeger, W., Abels, J., Hellemans, N., and Nieweg, H. O.: Effect of sodium bicarbonate and pancreatin on the absorption of vitamin $B_{12}$ and fat in pancreatic insufficiency. N. Engl. J. Med., 267: 1341 (1962).

37. Weber, A. M., Roy, C. C., Chartrand, L., Lepage, G., Dufour, O. L., Morin, C L., and Lasalle, R.: Relationship between bile acid malabsorption and pancreatic insufficiency in cystic fibrosis. Gut, 17: 295 (1976).

38. Wood, R. E., Boat, T. F., and Doershuk, C. F.: State of the art, cystic fibrosis Am. Rev. Respir. Dis., 113: 833 (1976).

39. It was presented, in part, at the 20th Annual Meeting of the Cystic Fibrosis Club, Atlanta. GA, May Ist 1979.

40. Requests for reprints should be addressed to: A. M. Weber, M.D., Hôpital SainteJustine, 3175 Ste-Catherine Road, Montreal, P.Q., Canada, H3T IC5.

41. This research was supported by a grant from the Medical Research Council of Canada and from the Canadian Cystic Fibrosis Foundation. Dr. Roulet was the recipient of a research fellowship from the Canadian Cystic Fibrosis Foundation.

42. Received for publication December 3, 1979.

43. Accepted for publication March 3, 1980. 